\title{
Impact Strength of Interply and Intraply Hybrid Laminates Based on Carbon-Aramid/Epoxy Composites
}

\author{
Çağrı Uzay ${ }^{1 *}$, Durmuş Can Acer ${ }^{2}$, Necdet Geren ${ }^{3}$ \\ 'Çukurova University, Department of Mechanical Engineering, Adana, Turkey \\ ORCID: Ç. Uzay (0000-0002-7713-8951), N. Geren (0000-0002-9645-0852)
}

\begin{abstract}
Hybridization plays an important role to achieve multi-functionality for the particular composite applications. Hybrid composites allow designers to obtain desired physical and mechanical properties that cannot be provided from a single type of fiber reinforcement such as combining high strength, light weight and good impact resistance together. In this study, the effect of hybridization on the Charpy impact strength was investigated considering the aramid and carbon fiber reinforced polymer (FRP) composites. For this reason, interply, intraply hybrid composite laminates, aramid FRP and carbon FRP were manufactured by hand lay-up followed by vacuum bagging method. The composite laminates were tested according to ISO 179-1: 2010 Standard using Charpy impact testing machine. The results were given comparatively and shown that energy absorption capacity of intraply hybrid composite laminate was found better than others.
\end{abstract}

Keywords: hybrid composites, intraply, interplay, Charpy test, impact resistance

\section{INTRODUCTION}

Composite materials are the combination of two or more materials to achieve certain improved or desired properties. And construction of the composite material can be performed by using a continuously distributed medium called as matrix. Metals, ceramic, glass and polymer materials are commonly used as matrix. The reinforcing material can be a metal, ceramic, glass, textile, polymer, or organic material in the form of lamina, fiber (short and long), particle, whisker, etc. Composite materials have emerged as a major class of structural elements due to their benefits such as lightweight, flexible, good impact strength, improved fatigue strength, high corrosion resistance, etc. Because of these advantages, composite materials are considered as a replacement of traditional materials which are used in the fields of aerospace, automotive, and other industries $[1,2]$.

The physical, mechanical and environmental properties of the composites are dependent upon its constituents. The geometry, size, type, orientation and the amount of fiber reinforcement materials, type of matrix are the affecting factors of the overall properties of the composite materials. Therefore, it is possible to obtain desired objectives by selecting suitable substitutes in good proportions from a wide variety of combinations. Composite materials can be called as eit- her laminate or hybrid according the type of reinforcement. If the same type of fiber fabrics are stacked with a matrix material, it is called as laminate. Although hybrid ones are also multilayered composites they are produced from two or more types of fiber reinforcements such as carbon/glass, carbon/aramid, glass/aramid, etc. Hybrid composites are fabricated to combine the best features of the each reinforcement element. In addition, some of the disadvantageous of the reinforcements can be eliminated. For example, carbon and glass fiber fabrics can be used to form a new hybrid composite material by taking the advantages of low cost of glass fibers and high modulus of carbon fibers [2,3]. Or Kevlar can be hybridized with glass fibers to improve durability and stiffness of the structure. For instance in marine applications, glass fiber and aramid fiber composites with epoxy resin are used instead of pure glass fiber composites. This hybridization provides lightweight, high impact resistance and better vibration damping properties. It was also reported that the compressive strength of aramid fiber composites with epoxy resin is low [4]. For these reasons, hybridization plays an important role to obtain desired physical and mechanical properties.

Mainly, four different types of hybrid composites are available in the literature as follow; "interply hybrid composites" which consists of different fiber types in different sequence, 
"intraply hybrid composites" which consist of two or more different types of fibers used in the same ply, "interply-intraply hybrid composites" which consists of interply and intraply laminates stacked in a certain sequence, and "resin hybrid composites" which can be formed by using two or more resins instead of altering the fiber types [4]. Attia et al. [5] made two hybrid configurations, intraply and inter-intraply by using polypropylene and E-glass unidirectional fibers and investigated the tensile, shear and flexural properties. They found that the mechanical properties of polypropylene composites with epoxy resin were increased considerably when hybridized with glass fiber according to proper stacking sequences. Bandaru et al. [6] hybridized aramid and basalt fabrics and compared to pure aramid laminates. The low velocity impact tests were showed that interply hybrid composites stacked with alternate sequence were found better. Uzay et al. [7] indicated that interplay hybridization of carbon and glass fiber fabrics with epoxy resin improved the impact toughness of the composite structure compared to carbon/epoxy laminate. This kind of applications can not only bring additional mechanical advantages but also can reduce the material cost such as using less number of carbon fiber ply. Dehkordi et al. [8] investigated the low velocity impact (16-30-40J) properties of intraply hybrid laminates consisted of basalt and nylon fabrics. Increasing the impact energy, the properties became more important depending upon the fiber contents in layer. But the low level of impact energy showed that the impact performance was not improved. Yahaya et al. [9] investigated ballistic impact performance of kenaf-Kevlar hybrid and Kevlar laminate, respectively. The study showed that kenaf-Kevlar hybrid has lower specific energy absorption than Kevlar laminate. Muhi et al. [10] investigated high velocity impact behavior of E-glass and Kevlar 29 fiber hybrid composites. They tested different laminates having different stacking sequences and proved the position of Kevlar is critical in order to obtain high amount of energy absorbed. Sapuan et al. [11] hybridized E glass and sugar palm fibers at different proportions by weight. They showed that the impact strength of glass and sugar palm fiber hybrid composites was significantly increased.

When the previous studies are scrutinized, it is seen that hybrid composites can possibly be made by combining various different materials. However, very limited researches are available related to mechanical properties of intraply hybrid laminates consist of aramid-carbon fibers such as tensile and flexural properties. But impact properties of the intraply aramid-carbon fiber laminates need further studies. Therefore, in this study, the hybrid effect of aramid and carbon fibers was investigated on impact toughness by using the Charpy impact test method. Both interplay and intraply hybrid laminates were tested and compared to pure laminates of carbon fiber fabrics and aramid fiber fabrics. Four different composite layers were manufactured by using epoxy resin with hand lay-up followed by vacuum bagging method.

\section{MANUFACTURING OF COMPOSITE LAMINATES}

Four different composite laminates were determined before manufacturing. Two of them were hybrid: interplay and intraply laminates. Interply hybrid composite consisted of aramid fiber fabrics and carbon fiber fabrics in an alternative stacking sequences and intraply hybrid composite consisted of aramid fibers and carbon fibers in the same ply. The fiber fabrics that are aramid, carbon and hybrid aramid/carbon (intraply fabric) were supplied by Dost Kimya Inc. in Turkey. In addition to these, pure laminates of both carbon fiber fabrics and aramid fiber fabrics were manufactured. Table 1 shows the composite laminate code and its explanations. And the stacking sequences of fiber reinforced polymer (FRP) composites have been shown in Figure 1 for the four different configurations.

Table 1 FRP Composite Laminate Code and Explanations

\begin{tabular}{|c|l|}
\hline $\begin{array}{c}\text { FRP lamina- } \\
\text { te code }\end{array}$ & \multicolumn{1}{|c|}{ Explanations } \\
\hline HF & $\begin{array}{l}\text { HF: hybrid fabric. Intraply lamination consists of carbon } \\
\text { and aramid. 12 plies of HF fabric were used to laminate FRP } \\
\text { composite }\end{array}$ \\
\hline A/C & $\begin{array}{l}\text { A/C: hybrid lamination. Interply composite consisted of five } \\
\text { layers of carbon fiber fabrics and six layers of aramid fabrics }\end{array}$ \\
\hline A & A: pure aramid FRP composite consisted of 10 aramid fabrics \\
\hline C & $\begin{array}{l}\text { C: pure carbon FRP composite consisted of 12 carbon fiber } \\
\text { fabrics }\end{array}$ \\
\hline
\end{tabular}

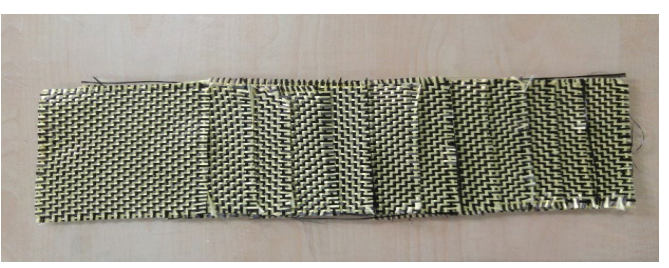

(a)

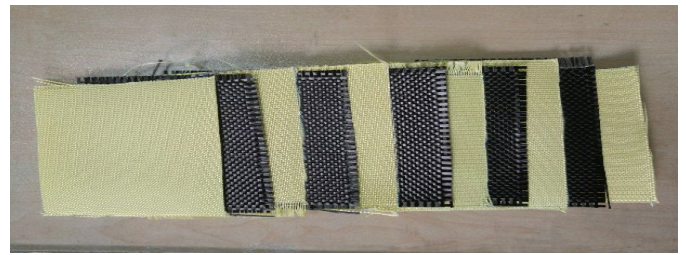

(b)

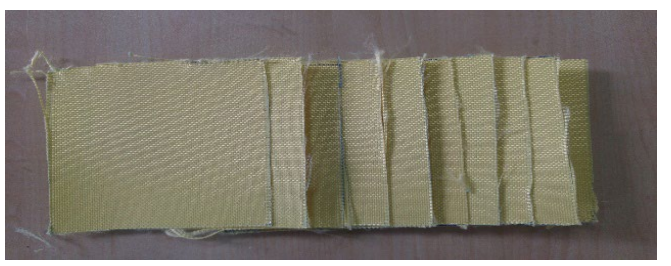

(c)

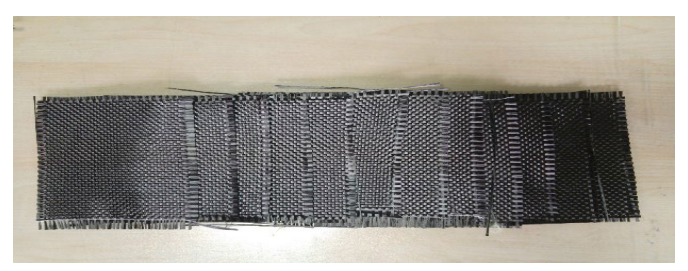

(d)

Figure 1: Stacking sequences of the fiber fabrics; (a) HF, (b) A/C, (c) A, (d) C

The fabrication was carried out by selecting an epoxy matrix, which is a thermoset resin due to following advantageous: 


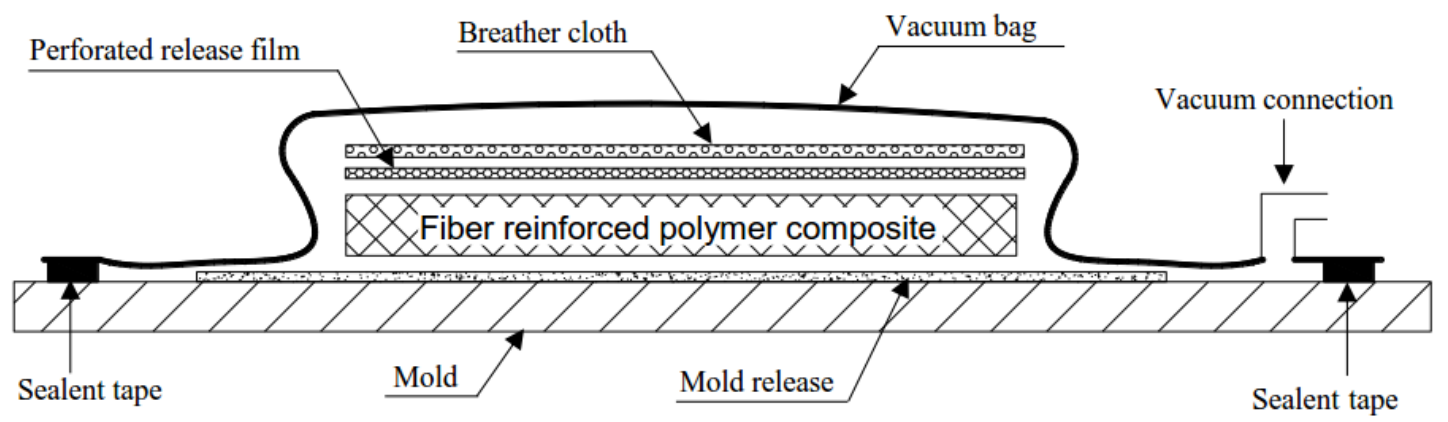

Figure 2: Schematic view of vacuum bagging method

compatible to curing agents, low shrinkage during curing, not affected by chemicals and solvents, strong bonding with wide range of fibers and additives [4]. MGS ${ }^{\mathrm{TM}}$ lamination epoxy resin set consists of L160 epoxy and H160 hardener was used for matrix material. Table 2 gives the physical and mechanical properties of resin set.



Figure 3: Manufacturing of FRP composite laminates

Table 2 Physical and Mechanical Properties of Matrix Materials [12]
\begin{tabular}{|c|c|c|}
\hline Physical and mechanical properties & L160 epoxy & H160 hardener \\
\hline Density $\left(\mathrm{kg} / \mathrm{m}^{3}\right)$ & $1,13-1,17$ & $0,96-1,00$ \\
\hline Viscosity $(\mathrm{mPa} . \mathrm{s})$ & $700-900$ & $10-50$ \\
\hline Bending strength $(\mathrm{MPa})$ & $110-140$ & - \\
\hline Modulus of elasticity (GPa) & $3,2-3,5$ & - \\
\hline Tensile strength (MPa) & $70-80$ & - \\
\hline Compressive strength (MPa) & $80-100$ & - \\
\hline
\end{tabular}

The amount of matrix material was determined equal to the amount of fiber fabrics. The weight ratio of epoxy to hardener was 100:25. Figure 2 represents the schematic view of vacuum bagging method (VBM). The manufacturing of four different composite laminates was performed using VBM as shown in Figure 3. Curing of laminated composites was carried out at room temperature under vacuum atmosphere.

\section{PREPARATION OF SPECIMENS FOR CHARPY IMPACT TEST}

Charpy impact test is a type of low velocity impact test method utilizes a drop weight pendulum. It is fast and simple to use for the relative evaluation of brittleness or toughness of specimens $[13,14]$.

After curing, FRP composite laminates were cut to standard test specimen dimensions according to ISO 179-1: 2010 Standard. The unnotched specimens were produced and flatwise-normal direction was used for blow. JBS-300N model Impact Testing Machine was used in Mechanical Engineering Laboratory of Çukurova University. The potential impact energy, impact velocity and raise angle of the machine were set to $150 \mathrm{~J}, 5,2 \mathrm{~m} / \mathrm{s}$ and $150^{\circ}$ respectively.

\section{RESULTS AND DISCUSSION}

FRP composite specimens were tested with five replications to satisfy the accuracy of the results and the absorbed energy by the test specimens were recorded as seen in Table 3.

Table 3 Absorbed Energy Values by the FRP Composite Specimens

\begin{tabular}{|c|c|c|c|c|c|c|}
\hline \multirow{2}{*}{$\begin{array}{c}\text { FRP com- } \\
\text { posite }\end{array}$} & \multicolumn{7}{|c|}{ Absorbed Energy, J } \\
\cline { 2 - 7 } & Test 1 & Test 2 & Test 3 & Test 4 & Test 5 & Average \\
\hline C & 2,25 & 2,19 & 2,33 & 2,30 & 2,17 & 2,25 \\
\hline A & 3,26 & 3,03 & 3,15 & 3,15 & 3,03 & 3,12 \\
\hline A/C & 4,24 & 3,43 & 3,84 & 3,53 & 3,33 & 3,68 \\
\hline HF & 4,24 & 4,35 & 3,49 & 3,53 & 3,68 & 3,86 \\
\hline
\end{tabular}

Using the data written in Table 3, the Charpy impact stren- 
gth of test specimens were calculated via Equation 1 [14] and the results were given in Table 4.

$$
a_{\mathrm{cN}}=\frac{E_{\mathrm{c}}}{h \cdot b} 10^{3}
$$

Where;

$a_{\mathrm{cN}}$ : impact strength $\left(\mathrm{kJ} / \mathrm{m}^{2}\right)$ of unnotched test specimen;

Ec : corrected energy (joules) absorbed by the breaking the test specimen;

h : thickness $(\mathrm{mm})$ of the test specimen;

b : width $(\mathrm{mm})$ of the test specimen.

Table 4 Impact Strength of the FRP Composite Specimens

\begin{tabular}{|c|c|c|c|c|c|c|}
\hline \multirow{2}{*}{$\begin{array}{c}\text { FRP com- } \\
\text { posite }\end{array}$} & \multicolumn{7}{|c|}{ Impact Strength, $\mathrm{kJ} / \mathrm{m}^{2}$} \\
\cline { 2 - 7 } & Test 1 & Test 2 & Test 3 & Test 4 & Test 5 & Average \\
\hline C & 56,25 & 54,75 & 58,25 & 57,5 & 54,25 & 56,20 \\
\hline A & 81,50 & 75,75 & 78,75 & 78,75 & 75,75 & 78,10 \\
\hline A/C & 106 & 85,75 & 96,00 & 88,25 & 83,25 & 91,85 \\
\hline HF & 106,00 & 108,75 & 87,25 & 88,25 & 92,00 & 96,45 \\
\hline
\end{tabular}

As it is seen from Table 3 and 4, the absorbed energy obtained from Charpy impact test was minimum for pure carbon FRP composite and it had the lowest Charpy impact strength. And pure aramid FRP composite was also found lower than the hybrid composite laminates. Hybrid composites, both interply and intraply laminates yielded better results compared to pure FRP composite laminates. Even though aramid fibers have superior impact resistance, the lamination of aramid fiber fabrics with epoxy matrix is difficult. Because epoxy resin penetration between the aramid fibers are not good. And the crosslinking of aramid fibers during polymerization of the epoxy matrix material was poor because of weak interfacial bonding. Adding carbon fiber fabrics between the aramid fiber layers improved the crosslinking and favorably affected the Charpy impact results. Intraply composite laminates has given the best results under impact loading. Figure 4 shows the absorbed energy and the Charpy impact strength of the FRP composite laminates comparatively.

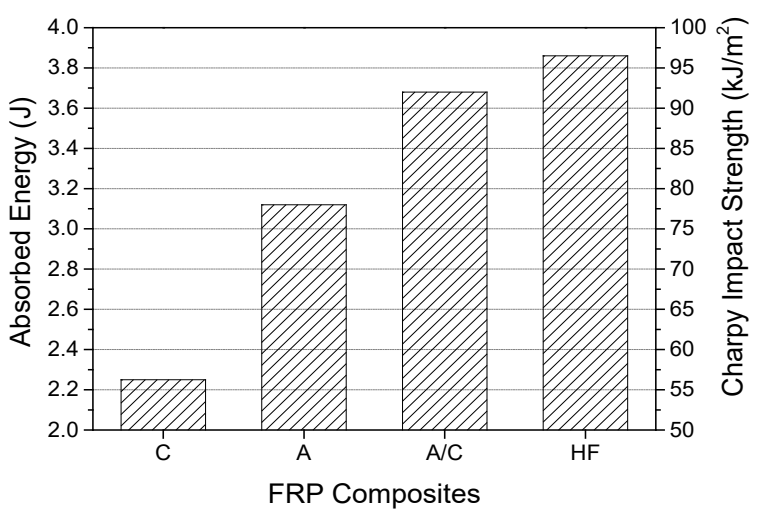

Figure 4: Absorbed energy and Charpy impact strength of the FRP composites

In order to see the effect of composite laminates on the Charpy impact strength, statistical one way ANOVA was also applied by using Design Expert software considering the experimental Charpy strength data. Figure 5 shows the normal plots of residuals for FRP composite laminates. A good fit of the data to a straight normal line was proved the normality assumption.
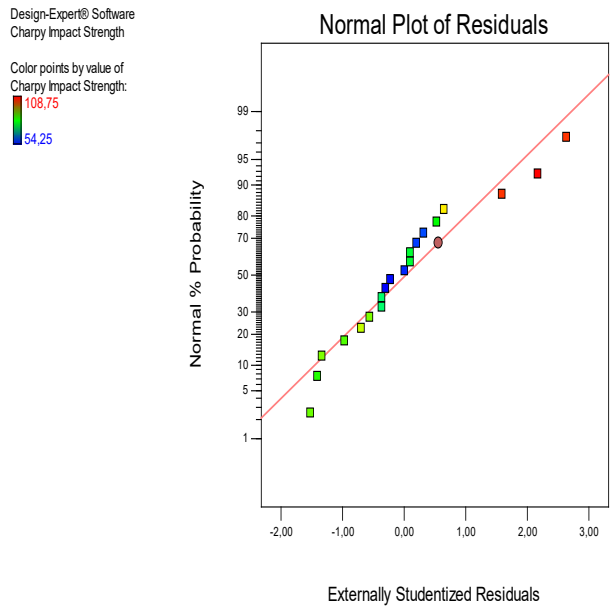

Figure 5: Normal plots of residuals for Charpy impact strength data

Full factorial design was performed with main effects model, and the ANOVA results were given in Table 5. At a confidence level of $95 \%$, the effect of composite laminate on Charpy impact strength was found statistically significant since $\mathrm{p}$ values are lower than 0,05 .

A strong correlation coefficient $\left(R^{2}=0,8609\right)$ for experimental results was obtained from regression analysis of composite laminates.

Table 5 One-way ANOVA results FRP composite laminates

\begin{tabular}{|c|c|c|c|c|c|c|}
\hline Source & $\begin{array}{c}\text { Sum of } \\
\text { Squares }\end{array}$ & df & $\begin{array}{c}\text { Mean } \\
\text { Square }\end{array}$ & F Value & $\begin{array}{c}\text { p-value } \\
\text { Prob }>\text { F }\end{array}$ & \\
\hline Model & 4896.93 & 3 & 1632.31 & 33.02 & $<0.0001$ & significant \\
\hline \begin{tabular}{c|c|c|c|c|c|c|} 
A-Composite \\
laminate
\end{tabular} & 4896.92 & 3 & 1632.31 & 33.02 & $<0.0001$ & \\
\hline Pure Error & 791.00 & 16 & 49.44 & & & \\
\hline Cor. Total & 5687.93 & 19 & & & & \\
\hline
\end{tabular}

\section{CONCLUSION}

The Charpy impact strength of hybrid intraply composite laminate consists of aramid and carbon fibers were evaluated. The results were compared to pure aramid fiber laminate, carbon fiber laminate, and hybrid interply laminate of aramid fiber and carbon fiber. The Charpy impact test results have shown that hybridization in terms of intraply laminates yield better results than others. Interply hybrid laminates give $63,4 \%$ and $17,6 \%$ higher results compared to pure carbon FRP and aramid FRP composites respectively. Intraply hybrid laminates give $71,6 \%$ and $23,5 \%$ higher results compared to pure carbon FRP and aramid FRP composites respectively.

One-way ANOVA results verified that the effect of composite laminates on Charpy impact strength was statistically significant. The significance change of the experimental re- 
sults was determined with a good correlation coefficient of $86,09 \%$.

Briefly, in weight critical and high strength applications, carbon FRP composites can commonly be used. In addition to this, intraply aramid-carbon hybrid laminates can also provide desired impact resistance for multi-functionality purposes.

\section{REFERENCES}

[1] Kar K. K. (2017). Composite Materials Processing, Applications, Characterizations. Springer-Verlag Berlin Heidelberg, Germany.

[2] M. Balasubramanian (2014). Composite Materials and Processing. CRC Press.

[3] Pegoretti, A., Fabbri, E., Migliaresi, C., and Pilati, F. (2004). Intraply and interply hybrid composites based on E-glass and poly(vinyl alcohol) woven fabrics: tensile and impact properties. Polymer International, 53(9): 1290-129?, DOl: 10.1002/ pi.1514.

[4] Mallick, P.K. (2007). Fiber-Reinforced Composites: Materials, Manufacturing, and Design, 3rd Edition CRC Press.

[5] [5] Attia, M.A., Abd El-baky, M.A. and Alshorbagy, A.E. (2017). Mechanical performance of intraply and inter-intraply hybrid composites based on e-glass and polypropylene unidirectional fibers. Journal of Composite Materials, 51(3): 381-394, DOI: $10.1177 / 0021998316644972$.

[6] Bandaru, A.K., Patel, S., Ahmad, S. and Bhatnagar, N. (2017). An experimental and numerical investigation on the low velocity impact response of thermoplastic hybrid composites. Journal of Composite Materials, 52(7): 877-889, DOI: 10.1177/0021998317714043.

[7] Uzay, C., Boztepe, M.H., Bayramoğlu, M. and Geren N. (2017). Effect of post-curing heat treatment on mechanical properties of fiber reinforced polymer (FRP) composites. Materials Testing, 59(4): 366372, DOI: $10.3139 / 120.111001$.

[8] Dehkordi, M.T., Nosraty, H., Shokrieh, M.M., Minak, G., Ghelli, D. (2013). The influence of hybridization on impact damage behavior and residual compression strength of intraply basalt/nylon hybrid composites. Materials and Design, 43 (2013): 283-290, DOI: 10.1016/j.matdes.2012.07.005

[9] Yahaya, R., Sapuan, S.M., Jawaid, M., Leman Z. and Zainudin, E.S. (2016). Investigating Ballistic Impact Properties of Woven Kenaf-aramid Hybrid Composites. Fibers and Polymers, 17(2): 275-281, DOI 10.1007/s12221-016-5678-6.

[10] Muhi, R.J., Najim, F., de Moura, M.F.S.F. (2009). The effect of hybridization on the GFRP behavior under high velocity impact. Composites: Part B, 40 (2009): 798-803, DOI:10.1016/j.compositesb.2009.08.002.

[11] Sapuan, S.M., Lok, H.Y., Ishak, M.R. and Misri, S. (2013). Mechanical properties of hybrid glass/sugar palm fibre reinforced unsaturated polyester composites. Chinese Journal of Polymer Science, 31(10): 1394-1403, DOI: 10.1007/s10118-013-1342-4.

[12] Hexion Specialty Chemicals (2006). Technical Information, Epoxy Resins, Germany.

[13] ASTM D6110-10, 2010. Standard test method for determining the charpy impact resistance of notched specimens of plastics. ASTM International, West Conshohocken, PA, United States.

[14] International Standard ISO 179-1: 2010. Plastics - Determination of Charpy impact properties Part 1: Non-instrumented impact test. 